\title{
Determinants of Sexual Risk Behaviour among Men and Women of Reproductive Age in South Africa
}

\author{
Olusegun Sunday Ewemooje ${ }^{1}$, Elizabeth Biney $^{2}$, Acheampong Yaw Amoateng ${ }^{3}$ \\ ${ }^{1}$ Population and Health Research Entity, Faculty of Humanities, North-West University (Mafikeng Campus), \\ North West, South Africa \\ ${ }^{2}$ Department of Statistics, Federal University of Technology, Akure, Nigeria
}

\begin{abstract}
Many years after the outbreak of HIV/AIDS, public health exertions have not been able to limit the spread of the diseases. This study, therefore, seeks to widen the scope of investigation in regard to the socio-demographic factors that determine risky sexual behaviours among all persons aged 15-59 years old. The present study used the 2016 South African Health and Demographic Survey data to examine the social and demographic determinants of risky sexual behaviours among people of reproductive ages (15-59), using the binary logistic regression model. The results showed that socio-demographic variables, namely; age, race, level of education, wealth index and relationship status, generally predict sexual risk-taking behaviours among South African men and women. Young people aged 20-24years; the Black Africans as well as never married people are overrepresented among those involved in unsafe sexual practices. However, those who are ever married or cohabiting are less at risk of engaging in risky sexual behaviour whereas education provides a degree of protection, more so for females than males. The findings from the study support actions to improve sex education for all individuals that are vulnerable.
\end{abstract}

Keywords: Early sexual debut; Gender; Health; Modeling; Unsafe sex

\section{Introduction}

Risky sexual behaviour - which include early sexual debut, unprotected sex, having multiple sexual partners, and inconsistent or non-use of contraceptive - is a contemporary public health issue and have been linked to increased exposure to other reproductive risks such as sexually transmitted infections, unwanted pregnancies and abortion (Alamrew et al., 2103). The increasing research focus on sexual risk practices is critical when considered in the context of the HIV/AIDS widespread. In spite of improved access to treatment and increased 
$2^{\text {nd }}$ International Conference on Modern Research in

SOCIAL SCIENCES

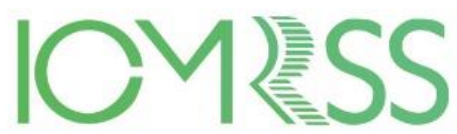

30 October - 01 November, 2019

MILAN, ITALY

governmental/non-governmental efforts in reducing its occurrence worldwide, HIV/AIDS vulnerability still continues in many developing countries (Coovadia \& Hadingham, 2005). In the African region, sub-Saharan Africa is unduly laden with HIV/AIDS epidemic - the leading cause of deaths in the region (WHO, 2005); besides, the region accounts for the highest number of new cases of HIV occurrences globally (Agaba et al., 2016).

South Africa alone has approximately eight million people living with HIV in 2017, though there was significant decrease in the number of newly cases in the same year (HSRC, 2018). Unsafe sexual practices are key factors hampering total eradication of the burden of AIDS despite global and local interventions (WHO, 2005).

\subsection{Review of the empirical literature}

Studies have shown the relationship between gender and risky sexual behaviours, with males more likely to engage in risky sexual behaviours than females (Etrawati et al., 2017; Frank et al., 2008; Gil-Lacruz \& Gil-Lacruz, 2016; Mahdavian \& Zolala, 2017). A crosssectional study of the determinants of risky sexual behaviour among foreign-born and Swedish-born young adults by Asamoah \& Agardh (2016) found gender to affect risky sexual behaviour; males were more likely to involve in non-use of condom during sex and having sex with unknown person on their first night. Also, Alamrew et al. (2013) found that male respondents were more than four times likely to have multiple sexual partners than females in a study evaluating risky sexual practices and associated factors for HIV/AIDS infection among private college students in Northwest Ethiopia; this is supported by a similar study by Negeri (2014) conducted in Ethiopia.

Age is also shown to have relationship with sexual risk behaviours which is measured by the timing of individual's first sexual encounter. Early sexual debut is seen as a risky sexual behaviour (De Irala et al, 2011; Osorio et al., 2017) and has been linked to risk sexual behaviours like unsafe sex and unwanted pregnancies (Frank et al., 2008; Letamo \& Mokgatlhe, 2013; Silas, 2013). Additionally, the level of education and wealth index has been found to affect individual's sexual behaviours. Less educated people are more prone to engage in unsafe sexual practices than more educated people. In line with this; Guilla \& Madise (2007) found a positive relationship between use of condoms and level of education, with the odds ratio of condom use increasing with years of schooling among adolescents in Burkina Faso. Similar findings on this include the works of Lwelamira, et al. (2015) and Maonga, et al., (2018).

Poverty has been shown to be a key risk factor that increases the chances of people engaging in unsafe sexual behaviours (Silas, 2013). Opposing this finding, Odimegwu \& Adedini (2013) found poverty to be a non-critical determinant of risky sexual behaviours in a Nigerian University. Limited studies have found rural/urban difference in risk sexual 
$2^{\text {nd }}$ International Conference on Modern Research in SOCIAL SCIENCES

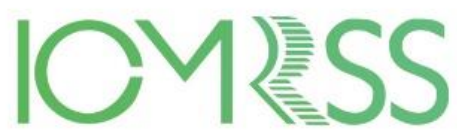

30 October - 01 November, 2019

MILAN, ITALY

behaviour, with rural residents undertaking unsafe sex than their urban counterparts (Guilla \& Madise, 2007).

Many years after the outbreak of HIV/AIDS, public health exertions have not been able to limit the spread of the diseases. This study, therefore, seeks to widen the scope of investigation in regard to the socio-demographic factors that determine risky sexual behaviours among all persons aged 15-59 years old by using 2016 South African Demographic and Health Survey data.

\section{Materials and Methods}

\subsection{Procedure}

The data for the study come from the 2016 South African Demographic and Health Survey (DHS). The DHS involved a total sample of 11083 households, consisting of 12132 participants from different parts of South Africa. Besides the collection of information on the knowledge and use of condoms, the number of sexual partners and age at first sex, the survey also collects information on socio-demographic characteristics.

\subsection{Measures}

The outcome variable under investigation is "risky sexual behaviour". This variable is binary and measured as " 1 " if the respondent had ever been involved in risky sexual behaviour and " 0 " if not. The "risky sexual behaviour" variable is a composite variable, which is the combination of three risky practices: sexual intercourse on or before age 14 years (early sexual debut), non-use of condom, and having multiple sexual partners. A respondent is said to be involved in risky sexual behaviour if he or she has been involved in one or more of these practices. We also examine effects of explanatory variables including; gender, age, race, place of residence, level of education, employment status, wealth index and relationship status on risky sexual behaviours of the respondents.

\subsection{Statistical Analysis}

The data are analysed at three levels, namely, univariate, bivariate and multivariate. At the univariate level, distribution of the socio-demographic characteristics of the respondents is shown using descriptive statistics such as frequencies and percentages. At the bivariate level, Pearson Chi-square test is used to measure the association between socio-demographic characteristics and risky sexual behaviours, using p-value $<0.05$ as the criterion for significance. Lastly, significant explanatory variables at bivariate level are moved to multivariate level. At the multivariate level of analysis, a binary logistic regression model is employed to identify variables that significantly predict risky sexual behaviours. The results are interpreted using the Odds Ratio (OR), and a variable is deemed a significant predictor of 
risky sexual behaviour if the p-value associated with the Odds Ratio is $<0.05$. All data are weighted and analysed using SPSS version 25.

\section{Results}

\subsection{Background characteristics}

Table 1 shows the distribution of the selected socio-demographic for the sample group. The table shows a significant gender differential in the sample as females constituted the majority $(70.2 \%)$ of the total respondents compared to male respondents $(29.8 \%)$. The majority (18.2\%) of the respondents belong to the adolescent age group (15-19 years), followed by the young adult groups $20-24$ years (16.6\%) and 25-29 years (15.6\%) respectively. Regarding race, most $(86.6 \%)$ of the respondents are identified as Black African, 9.5\% identified as Coloured, $2.7 \%$ as white and $1.2 \%$ as Indian/Asian. The majority $(60.8 \%)$ of the respondents are never married, $27.7 \%$ are ever married and $11.5 \%$ are cohabiting. With respect to the place of residence, more than half $(56.3 \%)$ of the respondents reside in urban areas compare to $43.7 \%$ living in rural areas.

Wealth index reveals that most $(43.1 \%)$ of the respondents considered themselves to live in the low wealth index households as they perceive themselves as poorer, unlike $33.8 \%$ who say they are richer or belonging to a higher wealth index households. Most $(58.7 \%)$ of the respondents are unemployed compare to those employed $(41.3 \%)$. In terms of the level of education, the majority (75.2\%) of the respondents have secondary education compare to those who have primary $(12.1 \%)$ and higher $(10 \%)$ education.

\subsection{Bivariate results}

Table 2 shows the results of the bivariate analyses using Chi-square tests in examining the association between different risky sexual behaviour and socio-demographic factors among male and female separately. Age, race, place of residence, level of education, wealth index and relationship status are all significantly associated with risky sexual behaviour while employment status is insignificantly associated with risky sexual behaviour regardless of gender.

\subsection{Multivariate results}

In Table 3, the results of the binary logistic regression model are presented. The model identified the significant determinants of sexual risk behaviour by both males and females showing that the likelihood of risky sexual behaviour decrease with age. However, there are significant differences in risky sexual behaviours according to gender. At all age groups, males are more likely to engage in risky sexual behaviour than their female counterparts. Black/African females are significantly more likely $(\mathrm{OR}=9.53, \mathrm{CI}=4.31-21.04)$ to engage in risky sexual behaviour than their male counterparts. 
$2^{\text {nd }}$ International Conference on Modern Research in

SOCIAL SCIENCES

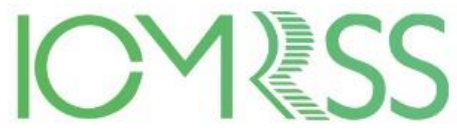

30 October - 01 November, 2019

MILAN, ITALY

Tab. 1: Socio-demographic distribution of the respondents

\begin{tabular}{|c|c|c|}
\hline Variables & Number & Percent $(\%)$ \\
\hline \multicolumn{3}{|l|}{ Age } \\
\hline $15-19$ years & 2210 & 18.2 \\
\hline 20-24 years & 2010 & 16.6 \\
\hline $25-29$ years & 1889 & 15.6 \\
\hline $30-34$ years & 1731 & 14.3 \\
\hline $35-39$ years & 1371 & 11.3 \\
\hline 40-44 years & 1299 & 10.7 \\
\hline $45-49$ years & 1183 & 9.8 \\
\hline 50 years + & 439 & 3.6 \\
\hline \multicolumn{3}{|l|}{ Gender } \\
\hline Male & 3618 & 29.8 \\
\hline Female & 8514 & 70.2 \\
\hline \multicolumn{3}{|l|}{ Race } \\
\hline Black/African & 10509 & 86.6 \\
\hline White & 327 & 2.7 \\
\hline Coloured & 1154 & 9.5 \\
\hline Indian/Asian & 142 & 1.2 \\
\hline \multicolumn{3}{|c|}{ Place of Residence } \\
\hline Urban & 6826 & 56.3 \\
\hline Rural & 5306 & 43.7 \\
\hline \multicolumn{3}{|c|}{ Level of Education } \\
\hline No education & 324 & 2.7 \\
\hline Primary & 1467 & 12.1 \\
\hline Secondary & 9129 & 75.2 \\
\hline Higher & 1212 & 10.0 \\
\hline \multicolumn{3}{|c|}{ Employment Status } \\
\hline Unemployed & 7125 & 58.7 \\
\hline Employed & 5007 & 41.3 \\
\hline \multicolumn{3}{|l|}{ Wealth Index } \\
\hline Poorer & 5230 & 43.1 \\
\hline Middle & 2800 & 23.1 \\
\hline Richer & 4102 & 33.8 \\
\hline \multicolumn{3}{|c|}{ Relationship Status } \\
\hline Never Married & 7375 & 60.8 \\
\hline Ever Married & 3357 & 27.7 \\
\hline Cohabiting & 1400 & 11.5 \\
\hline
\end{tabular}

It also shows that the likelihood of risky sexual behaviour increases with the level of education. Females are less likely ( $\mathrm{OR}=0.86, \mathrm{CI}=0.55-1.34$ ) to engage in risky sexual behaviour if they have higher/tertiary than males $(\mathrm{OR}=2.96, \mathrm{CI}=1.69-5.20)$ who have higher/tertiary education; this is true for all other levels of education. Similarly, female 


\section{$2^{\text {nd }}$ International Conference on Modern Research in}

SOCIAL SCIENCES

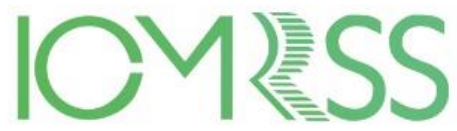

30 October - 01 November, 2019

MILAN, ITALY

respondents are less likely to engage in risky sexual behaviour if they had secondary $(\mathrm{OR}=$ $0.85, \mathrm{CI}=0.57-1.27)$ and primary education $(\mathrm{OR}=0.73, \mathrm{CI}=0.47-1.11)$. Educated males are more likely to engage in risky sexual behaviour while educated females are less likely to engage in risky sexual behaviour.

Tab. 2: Bivariate analyses of risky sexual behaviour by socio-demographic characteristics

\begin{tabular}{|c|c|c|c|c|c|c|}
\hline \multirow{3}{*}{$\begin{array}{l}\text { Explanatory } \\
\text { variables }\end{array}$} & \multicolumn{3}{|c|}{ Male } & \multicolumn{3}{|c|}{ Female } \\
\hline & & \% Risky & & & \% Risky & \\
\hline & Number & $\begin{array}{c}\text { Sexual } \\
\text { Behaviour }\end{array}$ & $\mathrm{p}$ value & Number & $\begin{array}{c}\text { Sexual } \\
\text { Behaviour }\end{array}$ & $\mathrm{p}$ value \\
\hline Age & & & $<.001$ & & & $<.001$ \\
\hline $15-19$ & 308 & 43.7 & & 559 & 37.1 & \\
\hline $20-24$ & 492 & 81.7 & & 952 & 67.6 & \\
\hline $25-29$ & 358 & 72.8 & & 847 & 60.6 & \\
\hline $30-34$ & 247 & 56.7 & & 564 & 43.6 & \\
\hline $35-39$ & 167 & 49.3 & & 406 & 39.3 & \\
\hline $40-44$ & 129 & 38.5 & & 319 & 33.1 & \\
\hline $45-49$ & 85 & 31.5 & & 219 & 24.0 & \\
\hline $50+$ & 97 & 22.1 & & 3866 & & \\
\hline Race & & & $<.001$ & & & $<.001$ \\
\hline Black/African & 1742 & 55.3 & & 3573 & 48.6 & \\
\hline White & 23 & 20.4 & & 29 & 13.6 & \\
\hline Coloured & 106 & 34.6 & & 256 & 30.2 & \\
\hline Indian/Asian & 12 & 24.5 & & 8 & 8.6 & \\
\hline Place of Residence & & & 0.002 & & & $<.001$ \\
\hline Urban & 1006 & 49.8 & & 2030 & 42.2 & \\
\hline Rural & 877 & 54.9 & & 1836 & 49.5 & \\
\hline Level of Education & & & $<.001$ & & & $<.001$ \\
\hline No education & 44 & 32.8 & & 65 & 34.2 & \\
\hline Primary & 228 & 37.7 & & 303 & 35.2 & \\
\hline Secondary & 1431 & 56.2 & & 3106 & 47.2 & \\
\hline Higher & 180 & 54.4 & & 392 & 44.5 & \\
\hline Employment Status & & & 0.289 & & & 0.616 \\
\hline Unemployed & 909 & 53.0 & & 2445 & 45.2 & \\
\hline Employed & 974 & 51.2 & & 1421 & 45.8 & \\
\hline Wealth Index & & & $<.001$ & & & $<.001$ \\
\hline Poorer & 877 & 54.7 & & 1773 & 48.9 & \\
\hline Middle & 470 & 55.7 & & 970 & 49.6 & \\
\hline Richer & 536 & 45.7 & & 1123 & 38.3 & \\
\hline Relationship Status & & & $<.001$ & & & $<.001$ \\
\hline Never Married & 1582 & 70.6 & & 3405 & 66.3 & \\
\hline Ever Married & 217 & 21.9 & & 356 & 15.1 & \\
\hline Cohabiting & 84 & 21.9 & & 105 & 10.3 & \\
\hline Total & 1883 & 52.0 & & 3866 & 45.4 & \\
\hline
\end{tabular}

Furthermore, Table 3 shows that irrespective of gender, wealth index has lower odds of engaging in a risky sexual behaviour for richer people. Looking at relationship status, the analysis shows that ever married and cohabiting people are significantly less likely to engage 
$2^{\text {nd }}$ International Conference on Modern Research in

SOCIAL SCIENCES

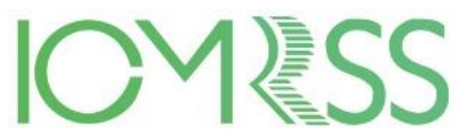

30 October - 01 November, 2019

MILAN, ITALY

in a risky sexual behaviour than those who have never married regardless gender. Finally, the log-likelihood ratio tests show that age $(p<.001)$, race $(p<.001)$, level of education $(p=0$ $.001)$, wealth index $(\mathrm{p}<.001)$ and relationship status $(\mathrm{p}<.001)$ have significant effects on risky sexual behaviour.

Tab. 3: Multivariate logistic regression model showing odds ratios predicting risky sexual behaviour by gender

\begin{tabular}{|c|c|c|c|c|}
\hline \multirow{2}{*}{ Explanatory variables } & \multicolumn{2}{|c|}{ Male } & \multicolumn{2}{|c|}{ Female } \\
\hline & Odd Ratio & CI & Odd Ratio & CI \\
\hline \multicolumn{5}{|l|}{ Age } \\
\hline $15-19$ & 1.00 & & 1.00 & \\
\hline $20-24$ & $7.69 * * *$ & $5.83-10.15$ & $6.17 * * *$ & $5.19-7.34$ \\
\hline $25-29$ & $9.40 * * *$ & $6.94-12.73$ & $8.55 * * *$ & $7.10-10.29$ \\
\hline $30-34$ & $7.19 * * *$ & $5.25-9.83$ & $5.79 * * *$ & $4.78-7.01$ \\
\hline $35-39$ & $7.48 * * *$ & $5.31-10.53$ & $5.08 * * *$ & $4.14-6.23$ \\
\hline $40-44$ & $5.10 * * *$ & $3.61-7.20$ & $3.94 * * *$ & $3.18-4.87$ \\
\hline $45-49$ & $4.47 * * *$ & $3.05-6.55$ & $2.70 * * *$ & $2.15-3.39$ \\
\hline $50+$ & $3.48 * * *$ & $2.44-4.96$ & & \\
\hline \multicolumn{5}{|l|}{ Race } \\
\hline Black/African & $6.42 * * *$ & $2.99-13.78$ & $9.53 * * *$ & $4.31-21.04$ \\
\hline White & 1.760 & $0.70-4.46$ & $2.89 *$ & $1.16-7.18$ \\
\hline Coloured & $2.27 *$ & $1.01-5.07$ & $5.51 * * *$ & $2.46-12.36$ \\
\hline Indian/Asian & 1.00 & & 1.00 & \\
\hline \multicolumn{5}{|l|}{ Place of Residence } \\
\hline Urban & .970 & $0.80-1.19$ & 1.050 & $0.92-1.20$ \\
\hline Rural & 1.00 & & 1.00 & \\
\hline \multicolumn{5}{|l|}{ Level of Education } \\
\hline No education & 1.00 & & 1.00 & \\
\hline Primary & 1.240 & $0.76-2.04$ & .730 & $0.47-1.11$ \\
\hline Secondary & $2.36 * * *$ & $1.46-3.81$ & .850 & $0.57-1.27$ \\
\hline Higher & $2.96 * * *$ & $1.69-5.20$ & .860 & $0.55-1.34$ \\
\hline \multicolumn{5}{|l|}{ Wealth Index } \\
\hline Poorer & 1.00 & & 1.00 & \\
\hline Middle & 1.060 & $0.86-1.32$ & 1.100 & $0.95-1.27$ \\
\hline Richer & .820 & $0.65-1.04$ & $0.73 * * *$ & $0.62-0.85$ \\
\hline \multicolumn{5}{|l|}{ Relationship Status } \\
\hline Never Married & 1.00 & & 1.00 & \\
\hline Ever Married & $0.08 * * *$ & $0.06-0.10$ & $0.06 * * *$ & $0.05-0.07$ \\
\hline Cohabiting & $0.06 * * *$ & $0.04-0.08$ & $0.03 * * *$ & $0.02-0.04$ \\
\hline
\end{tabular}

* Significant at 0.05 level, ** Significant at 0.01 level,

*** Significant at 0.001 level and 1.00 is reference category

\section{Discussion}

The present study sought to examine and identify the socio-demographic determinants of sexual risk behaviours among males and females of reproductive age in South Africa using the 2016 SADHS. Overall, the study found socio-demographic variables; age, race, level of education, wealth index and relationship status that generally determine sexual risk behaviours among South African men and women. Firstly, this study found that the prevalence of risky sexual behaviour is highest among the young adults age group (20-24year olds). The 
$2^{\text {nd }}$ International Conference on Modern Research in SOCIAL SCIENCES

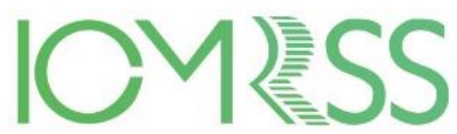

30 October - 01 November, 2019

MILAN, ITALY

overrepresentation of younger age in sexual risk practices is expected given that adolescence/young adulthood is a period of sexual experimentation (Odimegwu \& Adedini, 2013). The significant finding of the increasing rate of unsafe sexual behaviour among younger people is largely in accordance with previous studies in South Africa (Amoateng et al., 2014). Even within this age cohort, there was gender differential as males were disproportionately represented in those that have engaged in unsafe sexual practices. This finding is in-line with consensus in the literature where the male gender has been found to be at a higher risk of engaging in unsafe sex (Etrawati et al., 2008; Frank et al., 2008; Mahdavian \& Zolala, 2017; Asamoah \& Agardh, 2016; Negeri, 2014).

Secondly, the study also found that those who are ever married or cohabiting are less at risk of engaging in risky sexual behaviour. The finding of the less-prevalence of risky sexual behaviour among married people is in converse with Osuafor \& Ayiga's (2016) study of married and cohabiting women in Mahikeng, South Africa. This suggests that marriage prevent people from engaging in unsafe sex.

Another interesting finding is that of the effect of education on sexual risk behaviours. Usually, education has a protective effect on sexual behaviour as it improves the knowledge of and access to reproductive health services (Guiella \& Madise, 2007; Lwelamira et al., 2015; Maonga et al., 2018) but the result of this study shows that the role of education in determining risky sexual behaviours is mixed. The finding revealed that education provides a degree of protection, more so for females than males. For female respondents, the odds of engaging in unsafe sexual practices are reduced with education. Conversely, for male respondents, the higher their educational level, the higher their risk of unsafe sexual practices. This is corroborated by similar studies on South Africa by Hargreaves \& Glynn (2002) as well as Tenkorang, et al., (2011).

In conclusion; younger age, race, level of education, wealth index and relationship statuses were found to generally determine risky sexual behaviours among South African men and women of reproductive ages (15-59). The study has contributed important information regarding the determinants of unsafe sexual practices among a larger sample of the population. The results could be used to develop sexual education interventions to reduce the prevalence of risky sexual behaviours.

\section{References}

Agaba, P. A., Makai, R., Bankat, C. T., Chebu, P. R., Apena, T., Iyaji-Paul, O. and Idoko, J. A. (2016). Sexual behavior and risk factors for HIV infection among young people aged 1524 years in North-Central Nigeria. Journal of Medicine in the Tropics, vol. 18(2), pp. 6067. 
$2^{\text {nd }}$ International Conference on Modern Research in SOCIAL SCIENCES

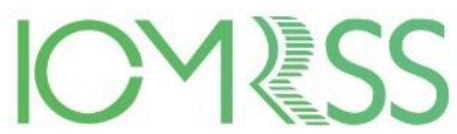

30 October - 01 November, 2019

MILAN, ITALY

Alamrew, Z., Bedimo, M. and Azage, M. (2013). Risky Sexual Practices and Associated Factors for HIV/AIDS Infection among Private College Students in Bahir Dar City, Northwest Ethiopia, ISRN Public Health, pp. 1-9.

Amoateng, A. Y., Kalule-Sabiti, I. and Arkaah, Y. J. (2014). The Effect of Socio-Demographic Factors on Risky-Sexual Behaviours of Adolescents in the North West Province of South Africa, African Population Studies, vol. 28(1), pp. 487-498.

Asamoah, B.O. and Agardh, A. (2016). Individual- and Family-Level Determinants of Risky Sexual Behavior Among Swedish- and Foreign-Born Young Adults 18-30 Years of Age, Residing in Skane, Sweden, Archive of Sexual Behavior, vol. 47, pp. 517-528.

Coovadia, H. M. and Hadingham, J. (2005). HIV/AIDS: global trends, global funds and delivery bottlenecks. Globalization and Health, pp. 1:13.

De Irala, J., Osorio, A., Carlos, S., Ruiz-Canela, M. and Lo'pez-del Burgo, C. (2011). Mean Age of First Sex: Do They Know What We Mean? Archives of Sexual Behaviour, vol. 40, pp. 853-855.

Etrawati, F., Martha, E. and Damayanti, R. (2017). Psychosocial determinants of risky sexual behaviors among senior high school students in Merauke District. Kesmas, National Public Health Journal, vol. 11(3), pp. 127-132.

Frank, S., Esterhuizen, T., Jinabhai, C. C., Sullivan, K. and Taylor, M. (2008). Risky sexual behaviours of high-school pupils in an era of HIV and AIDS, South African Medical Journal, vol. 98, pp. 394-398.

Gil-Lacruz, A. I. and Gil-Lacruz, M. (2016). Psychosocial Determinants of Risky Sexual Behaviour by Gender in Spain, Journal of Women's Health and Gynaecology, vol. 3(1), pp. 1-9.

Guiella, G. and Madise, N. J. (2007). HIV/AIDS and Sexual-Risk Behaviors among Adolescents: Factors influencing the use of condoms in Burkina Faso. African Journal of Reproductive Health, vol. 11(3), pp. 182-196.

Hargreaves, J. R. and Glynn, J. R. (2002). Educational attainment and HIV-1 infection in developing countries: a systematic review, Tropical Medicine and International Health, vol. 7(6), pp. 489-498.

Human Sciences Research Council (HSRC) (2018). The fifth South African national HIV prevalence, incidence, behaviour and communication survey, 2017 (SABSSM V): HIV impact assessment summary. Cape Town: HSRC Press.

Letamo, G. and Mokgatlhe, L. L. (2013). Predictors of Risky Sexual Behaviour among Young People in the Era of HIV/AIDS: Evidence from the 2008 Botswana AIDS Impact Survey III, African Journal of Reproductive Health / La Revue Africaine de la SantéReproductive, vol. 17(3) pp. 169-181. 
$2^{\text {nd }}$ International Conference on Modern Research in SOCIAL SCIENCES

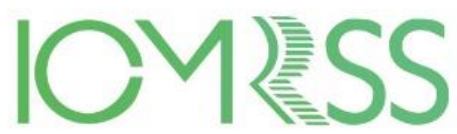

30 October - 01 November, 2019

MILAN, ITALY

Lwelamira, J., Safari, J. and Masanyiwa, Z. (2015). Prevalence and Determinants of Risky Sexual Behaviour Among Youth in Chamwino District, Central Tanzania, Rural Planning Journal, vol. 17(1), pp. 61-74.

Mahdavian, M. and Zolala, F. (2017). Determinants of Risky Behaviors in Youth: A GenderBased Study, Int J High Risk Behav Addict, vol. 6(1), e23604.

Maonga, B. B., Gondwe, T. P. and Machira, K. (2018). Determinants of Risky Sexual Behavior among the Youth in Malawi, DHS Working Paper No. 141. Rockville, Maryland, USA: ICF.

Negeri, E. L. (2014). Determinants of Risky Sexual Behavior, Relation between HIV Risk Perception and Condom Utilization among Wollega University Students in Nekemte Town, Western Ethiopia, Science, Technology and Arts Research Journal, vol. 3(3), pp. 75-86.

Odimegwu, C. and Adedini, S. A. (2013). Do Family Structure and Poverty Affect Sexual Risk Behaviors of Undergraduate Students in Nigeria? African Journal of Reproductive Health, vol. 17(4), pp. 137-149.

Osorio, A., Lopez-del Burgo, C., Carlos, S. and De Irala, J. (2017). The Sooner, the Worse? Association between Earlier Age of Sexual Initiation and Worse Adolescent Health and Well-being Outcomes, Front. Psychol., vol. 8, 1298.

Osuafor, G. N. and Ayiga, N. (2016). Risky sexual behaviour among married and cohabiting women and its implication for sexually transmitted infections in Mahikeng, South Africa, Sexuality \& Culture, vol. 20(1), pp. 805-823.

Silas, J. (2013). Poverty and Risky Sexual Behaviours: Evidence from Tanzania. DHS Working Papers No. 88. Calverton, Maryland, USA: ICF International.

Tenkorang, E. Y., Maticka-Tyandale, E. and Rajulton, F. A. (2011). Multi-level analysis of risk perception, poverty and sexual risk-taking among young people in Cape Town, South Africa, Health \& Place, vol. 17, pp. 525-535.

World Health Organization (WHO) (2005). Alcohol use and sexual risk behaviour: a crosscultural study in eight countries, Geneva, Switzerland: WHO Press. 